\title{
Developing a predictive model for prostate cancer screening intent among African American males
}

\author{
Quentin E. Moore* \\ Department of Baccalaureate and Graduate Nursing, Eastern Kentucky University, Richmond, Kentucky, USA
}

Received: May 16, 2020

Accepted: July 26, 2020

Online Published: August 14, 2020

DOI: $10.5430 /$ jnep.v10n11p81

URL: https://doi.org/10.5430/jnep.v10n11p81

\begin{abstract}
The purpose of this cross-sectional, predictive correlational study was to examine the relationship between African American male inmates' behavioral intentions with regard to the intention to screen for prostate cancer. To this end, the study devised and tested a model of relevant predictors, including Direct Attitude, Indirect Subjective Norms, Indirect Outcome Evaluation, and Health Literacy. Data were analyzed using descriptive and inferential statistics. The findings suggest that African American male inmates in the federal prison system may have slightly different priorities relative to non-incarcerated populations. The implications for nurses and other healthcare providers working in the prison system include: empowering inmates by building a trusting relationship; investigating ways to improve health literacy in this population, and developing an understanding of the factors that inspire African American inmates to engage in the decision-making process. The limitations of this study include a reliance on participant self-reports and a relatively small sample size, which limit the generalizability of the results. Nonetheless, future interventions may arise from providers' greater ability to understand and predict health-related behaviors and foster proactive health attitudes in the inmate population.
\end{abstract}

Key Words: African American men, Incarceration, Informed decision-making, Prostate cancer screening, Screening intent, Inmate

\section{INTRODUCTION}

Prostate cancer is the second-leading cause of cancer death in American men, second to only lung cancer, and the secondmost common type of cancer found among men in the United States. ${ }^{[1]}$ In 2020, there will be an estimated 191,930 new cases of prostate cancer diagnosed in the United States and an estimated 33,330 deaths from the disease. ${ }^{[1,2]}$ These incidence and mortality rates reflect decades of consistent improvement. Prostate cancers discovered at a local or regional stage tend to have a 5-year relative survival rate approaching $100 \%$. The 5-year survival rate decreases significantly (31\%) when the disease is diagnosed at a later stage. However, certain groups, such as African American men, remain at increased risk for developing prostate cancer. Currently, incidence rates are approximately 60\% higher in African Americans when compared to Caucasians, and African American men are twice as likely to die from this disease after they have been diagnosed. ${ }^{[1]}$ To add to this disparity, prostate cancer is usually found in later stages and progresses much more quickly in African American men when compared to Caucasian men. ${ }^{[3-5]}$

Although African American men have been identified as high risk, certain segments of the community remain largely underrepresented in research studies regarding this topic, which

\footnotetext{
* Correspondence: Quentin E. Moore; Email: quentin.moore@eku.edu; Address: Department of Baccalaureate and Graduate Nursing, Eastern Kentucky University, Richmond, Kentucky, USA.
} 
extends to men who are incarcerated. In the U.S., African Americans are incarcerated at disproportionately higher rates than Caucasians. According to the Bureau of Justice, African Americans are incarcerated in state and federal prisons at a rate almost six times that of Caucasians, and almost double the rate for Hispanics. ${ }^{[6]}$ When comparing the U.S. general population to that of the U.S. prison population, African Americans represent $33 \%$ of those sentenced to prison while only representing $12 \%$ of the U.S. adult population. ${ }^{[7]} \mathrm{De}-$ spite this demographic makeup of the inmate population, and the fact that African American males experience a higher risk of prostate cancer mortality, there are no studies that examine factors that influence prostate cancer screening activity in inmates. An examination of these factors may possibly facilitate earlier identification of those inmates at a higher risk for developing prostate cancer, which could lead to a better outcome for the individual.

\subsection{Background and significance}

While no studies investigating inmate decision making about prostate cancer screening have been conducted in the inmate population, there have been studies of the general public that examine factors behind African American men's decision to participate (or not) in prostate cancer screening. ${ }^{[8,9]}$ African American men are less likely than Caucasian men to screen for prostate cancer, and when prostate cancer screening is conducted and cancer is discovered, it is often found to be more aggressive and in advanced stages in the African American male population. ${ }^{[3-5]}$ African American men's lack of consistent screening patterns, lack of knowledge regarding prostate cancer, and differences in socioeconomic status are possible factors contributing to this disparity. ${ }^{[10,11]}$ Another factor that may contribute to this behavior is the individual's health literacy level. According to the Patient Protection and Affordable Care Act of 2010, Title V, health literacy is the degree to which an individual has the capacity to obtain, communicate, process, and understand basic health information and services to make appropriate health decisions. Studies have shown low health literacy levels to be connected with poor health outcomes such as: poorer health status, advanced stage at diagnosis, and higher mortality rates. ${ }^{[12-14]}$

To the author's knowledge, this will be the first study to explore prostate cancer screening intent, beliefs regarding screening, and health literacy in men who are incarcerated in the federal prison system. This population presents unique challenges that may increase their risk of experiencing cancer health disparities. The inmate population is largely composed of minorities, has less education and a lower income (prior to incarceration) than the general population, and may experience multiple chronic illnesses prior to incarceration. ${ }^{[15]}$
Research also shows that inmates physiologically age much faster than the general population. ${ }^{[16]}$ Medical evidence supports this statement as inmates begin to present with medical problems (around the age of 50) that typically present in the general population at a more advanced age. ${ }^{[17]}$ Possible reasons for this advanced aging include past drug and alcohol abuse, as well as high-stress lifestyles (prior to incarceration as well as stress related to life while incarcerated and improper medical care). ${ }^{[18]}$ Studies have also shown that this population is likely to have poor health-including multiple chronic health issues such as heart disease, respiratory disease, and cancer and little access to healthcare on the outside. ${ }^{[16,18]}$ Taking a proactive approach can potentially lead to the prevention and/or early detection of prostate cancer, thus improving the inmates' quality of life while decreasing future healthcare costs to the prison and/or when these inmates return to their communities.

The purpose of this study was to explore predictors of the intention to screen for prostate cancer in incarcerated African American males. The theoretical framework for this study was the Theory of Planned Behavior. The research question is: What is the influence of Attitude, Subjective Norms, and Perceived Behavioral Control on incarcerated African American males and their intent to screen for prostate cancer?

\subsection{Specific aims}

1) To describe the knowledge, attitudes, behaviors and behavioral intentions of study participants regarding prostate cancer screening, and to determine how these factors may be related to demographics.

2) To assess the extent to which the variables of the Theory of Planned Behavior explain an inmate's intention to be screened for prostate cancer.

3) To determine the amount of additional variance in the intent to screen that can be explained by health literacy after accounting for the variables in the Theory of Planned Behavior.

\subsection{Definition of terms}

For the purpose of this study, the following terms are defined as follows:

- Attitude: The degree to which a behavior is positively or negatively valued by the individual.

- Behavioral Beliefs: Beliefs that underlie a person's attitude toward the behavior.

- Subjective Norm: Perceived social pressure to adhere to or decline performance of a given behavior.

- Normative Beliefs: Beliefs concerned with the likelihood that significant others, such as family members, and friends approve or disapprove of a certain behavior. 
- Motivation to Comply: A person's general tendency to accept the directives of a given reference group or individual. - Perceived Behavioral Control: An individual's perceived ease or difficulty of performing the particular behavior.

- Intent: An indication of an individual's readiness to screen. - Health Literacy: The degree to which individuals have the capacity to obtain, process, and understand basic health information and services needed in order to make appropriate health decisions.

\subsection{Theoretical framework}

The Theory of Planned Behavior (TPB) is an extension of the Theory of Reasoned Action (TRA). ${ }^{[19]}$ The TRA is a behavioral model that seeks to explain the relationship between human attitudes and behaviors. The intent of the TPB, meanwhile, is to explain those behaviors that an individual can exert control over. According to the TPB, behavior is based on individual's intentions, which derive from his/her attitude toward the behavior, subjective norms surrounding the behavior, and his/her perceived difficulty (easy/difficult) of performing the given behavior (perceived behavioral control). All of the variables, except for behavior, are considered psychological (internal).

Attitude toward a behavior reflects the person's evaluation of the behavior. Two components are assumed to work together to influence attitude: behavioral beliefs and outcome evaluations. Subjective norm is the person's estimate of the social pressure to perform the given behavior. It is assumed that two components work together to make up subjective norms. The two components are normative beliefs and motivation to comply. Perceived behavioral control is the extent to which the person feels he/she can perform the behavior. It has two aspects as well. These are control beliefs and perceived control. Each variable (Attitude, Subjective Norm, Perceived Behavioral Control, and Intention) may also be measured directly by asking participants about specific behavioral beliefs and outcome evaluations. The TPB has been used successfully to predict health behaviors in areas such as: smoking, safe sex behaviors, testicular self-examinations, condom use, prostate cancer screening, suicide intent and multiple other healthy/unhealthy behaviors. In this study, the TPB will be used to investigate factors that influence an African American inmate's intention to engage in informed decision-making with regard to prostate cancer screening.

\section{METHODS}

A cross-sectional, predictive correlational design was used to examine the relationship between inmate behavioral intentions with regard to the intention to screen for prostate cancer.

Published by Sciedu Press

\subsection{Setting}

This research study was conducted at in a medical center within a federal prison, located in Lexington, Kentucky. This facility houses approximately 1,800 male inmates and has a racially diverse population. Of the 1,800 inmates housed at the facility, 808 (46\%) are African American and 186 (23\%) of these are age 45 and older.

\subsection{Ethical considerations}

IRB approval (IRB\# 15-0934-P2H) was received from the University Institutional Review Board (IRB) and the Federal Bureau of Prisons Office of Research and Evaluation (BRRB) prior to the study being conducted. First, the prison's SENTRY Inmate Management System was used to populate a list of all African American inmates who were 45 years old and older. SENTRY is a real-time system that collects and stores vital inmate information (ex: age, race, physical description, etc.). Next, a recruitment flyer was posted to the SENTRY e-mail bulletin board, which is viewable to the entire inmate population. In addition to the posting on the e-mail bulletin board, physical flyers were posted in several common areas including: 1) Inmate's housing units, 2) Education department, 3) Food Service, 4) Recreation, 5) Central Clinic, and 6) Religious Services department at the prison. Inmates who were interested in participating in the study were directed to submit an Inmate Request to a Staff Member Form (CopOut) (paper or electronic) to the principal investigator (PI). The PI was a member of the healthcare team at the prison. After receiving a Cop-Out, the PI populated a list of individuals interested in participating in the study. These inmates were placed on the Call-Out list (inmate appointments); at a later date, they were instructed to report to the Education department at a given time. The PI explained the study and reviewed the informed consent form with the group; individuals could opt out of participating at this stage. The inmates who signed the form were then given a questionnaire by the PI, either in a classroom setting or in a one-to-one setting in a private office if the participant chose to do so. The process of obtaining consent and completing the questionnaire took approximately 30 minutes. This paper questionnaire was then secured in a locked cabinet in a secured room in the college of nursing at the University.

\subsection{Sample}

For this study, the PI identified approximately 186 inmates who met the inclusion criteria and were part of an accessible population. All of these individuals were invited to participate in the study. Out of the 186 potential candidates, the PI recruited a convenience sample of 76 male inmates for this study. To be included, participants had to be: 1) 45 years old or older; 2) incarcerated in the federal prison system; 
3) able to read and understand the English language, 4) and have no prior history of prostate cancer. According to the American Cancer Society, ${ }^{[1]}$ a discussion about prostate cancer screening benefits and potential limitations should take place at age 50 or greater for those men who have an average risk of developing the disease and a life expectancy of at least 10 years. For men who are at a high risk for developing prostate cancer, such as African American men and those who have had a first-degree relative (father, brother, or son) diagnosed with prostate cancer at an early age (younger than age 65), the discussion should take place at the age of 45 . Lastly, for those men with an even higher risk (more than one first-degree relative who had prostate cancer at an early age), the ACS recommends the discussion take place at the age of 40. ${ }^{[1]}$ Based on the combination of these recommendations, the PI included men starting at age 45.

\subsection{Measures}

\subsubsection{Theory of planned behavior survey (Modified)}

The PI used a modified version of the previously validated Theory of Planned Behavior Survey (TPBS) to measure the constructs of the Theory of Planned Behavior. This instrument was developed by Gregory, ${ }^{[20]}$ a student at the University of Iowa. The instrument contains a total of 61 items for assessing the intention to participate in prostate cancer screening. This instrument was tested on a sample of 452 Caucasian men from Iowa who had no prior history of prostate cancer. The TPBS contains items that measure, both directly and indirectly, the constructs of behavioral intention (Attitude, Subjective Norms, and Perceived Behavioral Control). "Direct and indirect approaches to testing the TPB make different assumptions about the fundamental cognitive structures", ${ }^{[21]}$ which provides support for convergent validity. The content of the survey tool was created using elicitation interviews with a sample of the target population. Content validity was established during the pilot testing of the instrument. Following pilot testing, the instrument was updated to increase comprehension and readability.

This instrument contains nine items regarding patient screening history (e.g., Have you ever had a PSA test?), 29 Likert scale items on patients' beliefs and thoughts about prostate cancer screening (e.g., I want to be screened for prostate cancer next year; How much does your wife's opinion influence your decision to participate in prostate cancer screening?) and 11 demographic questions about marital status, education, etc. The questions regarding patient beliefs and thoughts are rated on a 7-point Likert scale, ranging from 1 to 7 (with 1 being less likely to perform the behavior and 7 being more likely). Questions for the survey were arranged according to the variable that they address in the Theory of Planned
Behavior. For this study, the PI removed all items from the original survey that were deemed irrelevant for the inmate population (e.g., questions about health insurance coverage and transportation).

\subsubsection{Attitude (Behavioral Beliefs and Outcomes Evalua- tions)}

Items for this part of the instrument were designed to address the behavioral beliefs and outcome evaluations of the population being studied. Behavioral beliefs are the beliefs about a behavior's consequences. The participants were asked to rate how much they agree with statements regarding having prostate cancer screening in the next year. There are four questions about behavioral beliefs (Questions 20, 21, 22, and 23). An example item is: 1) Receiving cancer PSA test in the next year will help detect cancer early if I have prostate cancer. Behavioral beliefs are measured using a 7-point Likert scale. Items with a potentially favorable outcome are scored so that agreement is positive (i.e., $1=$ Strongly Disagree, $2=$ Quite Disagree, $3=$ Slightly Disagree, $4=$ Neither Agree nor Disagree, 5 = Slightly Agree, $6=$ Quite Agree, $7=$ Strongly Agree). Potential negative outcomes are reverse scored (i.e., $7=$ Strongly Disagree, $6=$ Quite Disagree, $5=$ Slightly Disagree, $4=$ Neither Agree nor Disagree, $3=$ Slightly Agree, 2 $=$ Quite Agree, $1=$ Strongly Agree). Meanwhile, outcome evaluations reflect the value placed on an outcome, as well as positive or negative judgments about features of the behavior. Both categories were scored on Likert scales similar to the above. There are four questions addressing outcome evaluations (Questions 24, 25, 26, and 27). An example of an outcome evaluation question is: 2) Detecting prostate cancer early is very important to me. The total score is formed by adding all the items, with the higher scores indicating a greater intention to be screened.

\subsubsection{Subjective norm (Normative Beliefs and Motivation to Comply)}

Subjective norms are predicted by normative beliefs and motivation to comply. Normative beliefs are beliefs about whether or not someone who is important to the individual approves or disapproves of a behavior. There are five questions on normative beliefs (Questions 30, 31, 32, 33, and 34). An example item is: 1) My wife thinks I should get screened for prostate cancer. Beliefs were measured on a 7-point Likert scale (i.e., 1 = Strongly Disagree, 2 = Quite Disagree, 3 $=$ Slightly Disagree, $4=$ Neither Agree nor Disagree, $5=$ Slightly Agree, $6=$ Quite Agree, $7=$ Strongly Agree). Motivation to comply is defined as the motivation to do what referents think an individual should do. This construct is measured by five items scored in a Likert-type scale from $1=$ Not At All to 7 = Very Much (Questions 35, 36, 37, 38, and 39). An example item is as follows: 2) How much does your 
wife's or partner's opinion influence your decision to get a PSA screening test? The total score is formed by adding all items, with the higher scores indicating a greater intention to be screened.

\subsubsection{Perceive behavioral control (Control Beliefs and Perceived Power)}

Perceived behavioral control comprises two components: control beliefs and perceived power. Control beliefs reflect an individual's beliefs about the presence of factors that may facilitate or impede the performance of a given behavior. There are four control belief items that are rated on a Likert scale from 1 = Difficult to 7 = Easy (Questions 40, 41, 42, and 43). An example is: 1) Will information about PSA screening make getting a PSA test? (Easy/Difficult). Meanwhile, perceived power refers to beliefs about the power of factors (situation and internal) to impede or facilitate the performance of the behavior. The four perceived power items are scored on a Likert scale ranging from $1=$ Unlikely to 7 = Likely (Questions 44, 45, 46, and 47). The total score is formed by adding all items, with the higher scores indicating a greater intention to be screened.

\subsection{Direct measures and scoring}

\subsubsection{Attitude}

Three items were used to assess men's attitudes about the prostate cancer screening in the next year. These were rated on a Likert scale ranging from $1=$ Useless, to $4=$ Neither Useless nor Useful, to 7 = Useful (Questions 48, 49, 50). The question in all three items was the same with a different possible outcome (Useless/Useful, Worrisome/Reassuring, and Unnecessary/Important). An example item is: 1) In your opinion, having a PSA test to screen for prostate cancer in the next year will be? The total score is formed by adding all items, with the higher scores indicating a greater intention to be screened.

\subsubsection{Subjective norm}

Two items were used to measure the men's perceived social influence on getting screened for prostate cancer in the next year. These were rated using a Likert scale where $1=$ Strongly Disagree, 2 = Quite Disagree, $3=$ Slightly Disagree, $4=$ Neither Agree nor Disagree, $5=$ Slightly Agree, $6=$ Quite Agree, 7 = Strongly Agree (Questions 28 and 29). An example item is: 1) The people who are important to me think I should get a PSA test to screen for prostate cancer in the next year. The total score is formed by adding all items, with the higher scores indicating a greater intention to be screened.

\subsubsection{Perceived behavioral control}

Perceived control over receiving a prostate cancer screening in the next year was assessed using two items (Questions 16 and 51). The first item was scored on a Likert scale ranging from 1 = Strongly Disagree, to $7=$ Strongly Agree: 1) If I want to, I can get a PSA test to screen for prostate cancer in the next year? The second item was scored on a Likert scale ranging from $1=$ No Control to $7=$ Complete Control: 2 ) How much control do you have over getting a PSA test to screen for prostate cancer in the next year? The total score is formed by adding all items, with the higher scores indicating a greater intention to be screened.

\subsubsection{Intention}

Two items were used to assess an inmate's intentions to be screened for prostate cancer in the next year. These were scored on a Likert scale ranging from $1=$ Strongly Disagree, $2=$ Quite Disagree, 3 = Slightly Disagree, $4=$ Neither Agree nor Disagree, 5 = Slightly Agree, $6=$ Quite Agree, $7=$ Strongly Agree (Questions 13 and 14). Example items include: 1) I want to receive a PSA test to be screened for prostate cancer in the next year. 2) I plan to receive a PSA test to screen for prostate cancer in the next year. The total score is formed by adding all items, with the higher scores indicating a greater intention to be screened.

\subsubsection{Health literacy}

The Newest Vital Sign (NSV) is designed to measure an individual's health literacy. ${ }^{[22]}$ Studies have shown that individuals with limited health literacy have less knowledge of their health problems, poorer health status, and experience more hospitalizations. ${ }^{[23]}$ The instrument is usually administered by a nurse or other trained clinical staff member, who will verbally ask six questions pertaining to a nutrition label. The participant refers to the nutrition label to answer the questions. All questions are asked in sequence (even if prior questions are answered incorrectly). Scoring for NVS ranges from 0-6 (1 point for each correct answer). Scoring for the NVS is: 0-1 indicates a high likelihood of limited literacy, 2-3 indicates a possibility of limited literacy, and 4-6 almost always indicates adequate literacy. Administration of the instrument takes approximately three minutes and it is available in two languages (English (NVS-E) and Spanish (NVS-S)).

\subsection{Data analysis}

The data were analyzed using the Statistical Packages for Social Sciences (SPSS) version 22. Independent variables included demographic and personal factors (age, marital status, education, family history of prostate cancer, and health literacy) as well as constructs of the Theory of Planned Behavior (Attitude, Social Norms, and Perceived Behavioral Control). 
The dependent (outcome) variable was the inmate's intention to be screened for prostate cancer.

Descriptive statistics, including means and standard deviations or frequency distributions, were used to summarize the study variables. Two-sample $t$-tests and Pearson's product moment correlation were used to assess relationships between demographic and study variables and among study variables. Multiple linear regression was used to assess the potential predictors of intention to be screened for prostate cancer. Variance inflation factors were calculated to determine whether multicollinearity was influencing regression parameters. Hierarchical multiple regression analyses were utilized to assess if scores on the health literacy questionnaire explained a significant amount of variance in inmates' intention above those variables that were found to be significant in the two forward regression analyses outlined above.

\subsubsection{Instrument reliability and validity}

For the TPBS, convergent validity was demonstrated by Spearman's correlation between the direct and indirect summary scores. The summary scores for attitude $(r=0.62, p$ $<.0001, \mathrm{n}=360)$ and subjective norm $(\mathrm{r}=0.82, p<.0001$, $\mathrm{n}=86$ ) were very strongly correlated. The summary score for perceived behavioral control was modestly correlated ( $\mathrm{r}$ $=0.26, p<.0001, \mathrm{n}=356$ ). These findings suggest that the summary scores are measuring the same concept. Construct validity was also supported through the use a structural equation modeling of the relationship between the operational measures and theoretical constructs. In this equation, all the $t$ values were statistically significant, thereby providing further evidence that the measures assess the appropriate constructs. The minimum fit function Chi-square was statistically significant $\left(\chi^{2}=125.4 ; p<.05\right)$, demonstrating good instrument reliability. The normed fit index (NFI) was 0.97 , which suggests an acceptable model fit. The goodness-of-fit was 0.94 .

In order to achieve a power level of $80 \%$, the study only needed 65 participants, an alpha level of .05 , and up to 7 predictors, which facilitated the linear regression $\mathrm{F}$ test to detect an R-square as small as $0.20 .{ }^{[25]}$ This calculation did indeed reveal a power level that was slightly greater than .80 .

Note that this study used the English version of the Newest Vital Sign instrument. In prior studies, the internal consistency of the instrument demonstrated a Cronbach alpha of 0.76 and achieved Criterion validity $(\mathrm{r}=0.59, p<.001) .{ }^{[24]}$

\section{RESUlts}

Seventy-six men initially agreed to participate in the study However, only 67 participants completed the entire survey and were thus included in the analysis. All participants were
African American men whose age ranged from 45 to 70 years, with a mean age of 52 years. The majority $(65.0 \%$; $n$ $=50$ ) were single or divorced; only 16 participants (20.8\%) reporting being married. Meanwhile, $88 \%(n=67)$ of the men reported an education level of high school graduate or higher. Most of the men (83.5\%) viewed themselves as being in good health or better. The sample characteristics are presented in Table 1.

The relationship between knowledge and intention was assessed using a Pearson's Correlation. Knowledge showed a very weak negative relationship $(r=-.085, p=.483, \mathrm{~N}=70)$ to the intention to screen for prostate cancer.

There was a significant difference in intention based on whether the participant had a relative diagnosed with prostate cancer $(t=2.5, p=.014)$. Those who had a relative with this disease had higher scores than those who did not $[\mathrm{M}=6.7$ ( $\mathrm{SD}=0.8)$ and $\mathrm{M}=5.8(\mathrm{SD}=1.9)$, respectively].

An analysis of demographic variables and their relationship with intent revealed that marital status was not related to intent, $\mathrm{F}(3,62)=6.97, p=.058$. A $t$-test revealed that subjects who knew an individual diagnosed with prostate cancer (M $=6.20, \mathrm{SD}=1.46$ ) did not differ from subjects who did not know someone diagnosed with prostate cancer $(M=5.75$, $\mathrm{SD}=2.09), \mathrm{t}(59)=.998, p=.322$. The age of the subjects, $\mathrm{r}(74)=.075, p=.538$ and education of subjects, $\mathrm{r}(69)=-.109$, $p=.374$ were not related to intention. The subjects' selfassessment of their health was not related to their intention, $r(67)=-.056, p=.647$.

Forward Stepwise Regressions were utilized to assess the relationship of the direct and indirect measures to the subjects' intention to obtain a prostate examination. An alpha of .05 was used to determine if a variable should enter the model. The assumptions underlying the regression analyses were tested and will be included below. The intercorrelations of the direct and indirect measures of planned behavior, and intention are presented in Table 2. The regression analysis for the direct measures will be presented first, followed by the regression analysis for the indirect measures.

The measures of Direct Attitude, Direct Perceived Behavioral Control and Direct Subjective Norm were considered for entry into the Forward Regression Analysis to determine which of these variables significantly predicted the subjects' intention to obtain a prostate examination. The results, including the standardized and unstandardized coefficients and $t$-tests, are presented in Table 3. Direct Attitude entered into the regression on the first step, $\mathrm{t}(65)=6.40, p<.001$, adj. $\mathrm{R}^{2}$ $=.377$. The variables not included in the analysis at step one are included in Table 3. Both Direct Perceived Behavioral 
Control, $\mathrm{t}(64)=1.34, p=.186$, and Direct Subjective Norm, variance beyond Direct Attitude, and therefore did not enter $\mathrm{t}(64)=1.03, p=.307$, did not explain a significant amount of into the regression analysis.

Table 1. Sample demographic characteristics $\left(n=76^{*}\right)$

\begin{tabular}{ll}
\hline Variable & N (\%) or mean (SD) \\
\hline Marital Status & $16(20.8)$ \\
Married & $25(32.5)$ \\
Never married & $25(32.5)$ \\
Divorced & $2(2.6)$ \\
Widowed & $1(1.3)$ \\
Separated & $7(9.1)$ \\
Unmarried couple & \\
Education & $3(3.9)$ \\
Grade 1-8 & $6(7.8)$ \\
Grade 9-11 & $38(49.4)$ \\
Grade 12 or GED & $24(31.2)$ \\
College 1-3 years & $5(6.5)$ \\
College 4 or more years & \\
Health Status & $9(11.7)$ \\
Excellent & $20(26.0)$ \\
Very good & $27(35.1)$ \\
Good & $16(20.8)$ \\
Fair & $4(5.2)$ \\
Poor & $52.34( \pm 7.04)$ \\
Age & The N value reflects the total number of participants who provided the above data not the 67 who comprised the final analysis. \\
\hline
\end{tabular}

*The $\mathrm{N}$ value reflects the total number of participants who provided the above data, not the 67 who comprised the final analysis.

Table 2. Pearson correlation coefficients among the direct, indirect, and intention measures assessed in this study $\left(\mathrm{n}=76^{*}\right)$

\begin{tabular}{|c|c|c|c|c|c|c|c|c|c|c|c|}
\hline & $\begin{array}{l}\text { Health } \\
\text { Literacy }\end{array}$ & $\begin{array}{l}\text { Direct } \\
\text { Perceived } \\
\text { Behavioral } \\
\text { Control } \\
\end{array}$ & $\begin{array}{l}\text { Direct } \\
\text { Attitude }\end{array}$ & $\begin{array}{l}\text { Direct } \\
\text { Subject } \\
\text { Norm }\end{array}$ & Intention & $\begin{array}{l}\text { Indirect } \\
\text { Behavioral } \\
\text { Beliefs }\end{array}$ & $\begin{array}{l}\text { Indirect } \\
\text { Outcome } \\
\text { Evaluation }\end{array}$ & $\begin{array}{l}\text { Indirect } \\
\text { Normative } \\
\text { Beliefs }\end{array}$ & $\begin{array}{l}\text { Indirect } \\
\text { Motivation } \\
\text { to Comply }\end{array}$ & $\begin{array}{l}\text { Indirect } \\
\text { Control } \\
\text { Beliefs }\end{array}$ & $\begin{array}{l}\text { Indirect } \\
\text { Perceived } \\
\text { Power }\end{array}$ \\
\hline \multicolumn{12}{|l|}{ Direct } \\
\hline Perceived & -.110 & & & & & & & & & & \\
\hline Behavioral & .370 & & & & & & & & & & \\
\hline \multicolumn{12}{|l|}{ Control } \\
\hline Direct & -.05 & .150 & & & & & & & & & \\
\hline Attitude & .681 & .226 & & & & & & & & & \\
\hline Direct & -.170 & .402 & & & & & & & & & \\
\hline $\begin{array}{l}\text { Subject } \\
\text { Norm }\end{array}$ & .162 & .001 & $<.001$ & & & & & & & & \\
\hline \multirow{2}{*}{ Intention } & .221 & .221 & .606 & .394 & & & & & & & \\
\hline & .066 & .071 & $<.001$ & .001 & & & & & & & \\
\hline Indirect & .019 & .339 & .460 & .398 & .480 & & & & & & \\
\hline $\begin{array}{l}\text { Behavioral } \\
\text { Beliefs }\end{array}$ & .878 & .005 & $<.001$ & .001 & $<.001$ & & & & & & \\
\hline Indirect & -.053 & .274 & .339 & .009 & .310 & .333 & & & & & \\
\hline $\begin{array}{l}\text { Outcome } \\
\text { Evaluation }\end{array}$ & .669 & .027 & .005 & .944 & .011 & .006 & & & & & \\
\hline Indirect & -.005 & .575 & .496 & .763 & .584 & .463 & .082 & & & & \\
\hline $\begin{array}{l}\text { Normative } \\
\text { Beliefs }\end{array}$ & .969 & $<.001$ & $<.001$ & $<.001$ & $<.001$ & $<.001$ & .511 & & & & \\
\hline Indirect & & & & & & & 103 & & & & \\
\hline $\begin{array}{l}\text { Motivation } \\
\text { to Comply }\end{array}$ & .643 & .010 & $<.001$ & $<.001$ & .002 & $<.001$ & .406 & $<.001$ & & & \\
\hline Indirect & & & & & & & & & & & \\
\hline $\begin{array}{l}\text { Control } \\
\text { Beliefs }\end{array}$ & .934 & $\begin{array}{l}<.001 \\
<.001\end{array}$ & .137 & .006 & .136 & .095 & .141 & $\begin{array}{l}<.001 \\
<.010\end{array}$ & .343 & & \\
\hline Indirect & & & .392 & .387 & .370 & .285 & .213 & .531 & .435 & .432 & \\
\hline $\begin{array}{l}\text { Perceived } \\
\text { Power }\end{array}$ & $\begin{array}{l}.2 / 4 \\
.041\end{array}$ & $\begin{array}{l}.536 \\
<.001\end{array}$ & .392 & . .001 & .02 .02 & .018 & .083 & $\begin{array}{l}.031 \\
<.001\end{array}$ & $<.001$ & $<.001$ & \\
\hline
\end{tabular}


The assessment of the assumptions that underlie the regression analysis utilized a number of procedures. The linearity assumption, which was assessed by inspecting partial regression plots and a plot of studentized residuals against the predicted values, indicated that Direct Attitude, Direct Perceived Behavioral Control and Direct Subjective Norm had a linear relationship with intention. The Durbin-Watson statistic of 2.11 indicated that there was an independence of residuals. The homoscedasticity assumption, as assessed by a visual inspection of a plot of studentized residuals versus predicted values, indicated that this assumption was not vio- lated. Multicollinearity was not an issue, as all measures of tolerance were .75 and above. An assessment of outliers was conducted by an inspection of subjects' absolute standardized residuals. While two subjects had a residual above three, no leverage values were above .5 and no Cook's distances were above one, indicating that these subjects did not have a significant impact on the regression analysis. In addition, an examination of these two subjects' data revealed no data entry errors. Therefore, both subjects were retained in the analyses. The assumption of normality was met, as assessed by an inspection of a frequency distribution of the residuals.

Table 3. Multiple linear regression summary table for forward regression analysis utilizing direct measures as independent variables $(n=65)$

\begin{tabular}{|c|c|c|c|c|c|c|}
\hline & \multicolumn{2}{|c|}{$\begin{array}{l}\text { Unstandardized } \\
\text { Coefficients }\end{array}$} & \multicolumn{3}{|c|}{ Standardized Coefficients } & \multirow{2}{*}{$\begin{array}{l}\text { Collinearity } \\
\text { Statistics } \\
\text { VIF }\end{array}$} \\
\hline & $\mathbf{B}$ & Std. Error & Beta & $t$ & $p$ & \\
\hline \multicolumn{7}{|l|}{ Variable(s) in the Equation } \\
\hline Direct Attitude & 1.120 & .175 & .622 & 6.396 & $<.001$ & 1.000 \\
\hline \multicolumn{7}{|l|}{ Variable(s) in the Equation } \\
\hline Direct Perceived Behavioral Control & & & .130 & 1.34 & .186 & 1.023 \\
\hline Direct Subjective Norm & & & .116 & 1.03 & .307 & 1.35 \\
\hline
\end{tabular}

The measures of Indirect Behavioral Beliefs, Indirect Outcome Evaluation, Indirect Normative Beliefs, Indirect Motivation to Comply, Indirect Control Beliefs and Indirect Perceived Power were considered for entry into the Forward Regression Analysis to determine which of these variables significantly predicted the subjects' intention to obtain a prostate examination. The results, including the standardized and unstandardized coefficients and t-tests, for variables included in the analysis, are presented in Table 4. Indirect Normative Beliefs entered into the regression on the first step, $\mathrm{t}(65)=5.82, p<.001$, adj. $\mathrm{R}^{2}=.332$. Indirect Outcome Evaluation entered the analysis at step two, $\mathrm{t}(64)=2.74, p$ $=.008$, adj. $\mathrm{R}^{2}=.393$. Indirect Behavioral Beliefs, $\mathrm{t}(63)=$ $1.63, p=.107$, Indirect Motivation to Comply, $\mathrm{t}(63)=-1.25$, $p=.214$, Indirect Control Beliefs, $\mathrm{t}(63)=-1.17, p=.248$ and Indirect Perceived Power, $\mathrm{t}(63)=.095, p=.925$, did not explain a significant amount of variance beyond Indirect Normative Beliefs and Indirect Outcome Evaluation, and therefore did not enter into the regression analysis.

Table 4. Multiple linear regression summary table for forward regression analysis utilizing indirect measures as independent variables $(\mathrm{n}=65)$

\begin{tabular}{|c|c|c|c|c|c|c|}
\hline & \multicolumn{2}{|c|}{$\begin{array}{l}\text { Unstandardized } \\
\text { Coefficients }\end{array}$} & \multicolumn{3}{|c|}{ Standardized Coefficients } & \multirow{2}{*}{$\begin{array}{l}\text { Collinearity Statistics } \\
\text { VIF }\end{array}$} \\
\hline & B & Std. Error & Beta & $t$ & $p$ & \\
\hline \multicolumn{7}{|l|}{ Variable(s) in the Equation } \\
\hline Indirect Normative Beliefs & .724 & .124 & .585 & 5.82 & $<.001$ & 1.000 \\
\hline Indirect Outcome Evaluation & .653 & .239 & .264 & 2.74 & .008 & 1.007 \\
\hline \multicolumn{7}{|l|}{ Variable(s) in the Equation } \\
\hline Indirect Behavioral Beliefs & & & .186 & 1.63 & .107 & 1.45 \\
\hline Indirect Motivation to Comply & & & -.180 & -1.25 & .214 & 2.27 \\
\hline Indirect Control Beliefs & & & -.124 & -1.17 & .248 & .123 \\
\hline Indirect Perceived Power & & & .011 & .095 & .925 & 1.46 \\
\hline
\end{tabular}


As with the direct measures, the assessment of the assumptions that underlie the regression analysis utilized a number of procedures. The linearity assumption, which was assessed by inspecting partial regression plots and a plot of studentized residuals against the predicted values, indicated that Indirect Behavioral Beliefs, Indirect Outcome Evaluation, Indirect Normative Beliefs, Indirect Motivation to Comply, Indirect Control Beliefs and Indirect Perceived Power had a linear relationship with Intention. The Durbin-Watson statistic of 1.93 indicated that there was an independence of residuals. The homoscedasticity assumption, as assessed by a visual inspection of a plot of studentized residuals versus predicted values, indicated that this assumption was not violated. Multicollinearity was not an issue, as all measures of tolerance were .44 and above. An assessment of outliers was conducted by an inspection of subjects' absolute standardized residuals. None of the subjects had a standardized residual above three, no leverage values were above .5 , and no Cook's distances were above one, indicating that none of the subjects would be considered outliers. The assumption of normality was met, as assessed by an inspection of a frequency distribution of the regression residuals.

A series of hierarchical multiple regression analyses were utilized to assess if scores on the health literacy question- naire explained a significant amount of variance in intention to obtain a prostate examination above those variables that were found to be significant in the two forward regression analyses outlined above. Two hierarchical analyses were conducted, the first assessing if health literacy scores explained variance beyond and above Direct Attitude scores and the second assessing if health literacy scores explained variance beyond Indirect Normative Beliefs and Indirect Outcome Evaluation scores.

The results of the former analysis revealed that health literacy scores explained a significant amount of variance in Intention, $\mathrm{t}(65)=2.67, p=.008, \mathrm{R}^{2}$ change $=.062$, beyond Direct Attitude. The regression coefficients are presented in Table 5. The results of the latter analysis revealed that health literacy scores explained a significant amount of variance in Intention beyond Indirect Outcome Evaluation and Indirect Normative Beliefs, $\mathrm{t}(64)=2.47, p=.016, \mathrm{R}^{2}$ change $=.052$. The regression coefficients are presented in Table 6. An assessment of the assumptions that underlie the regression analyses revealed that none of the assumptions were violated. These findings may point to health literacy as a potential variable of consideration when examining health beliefs and intention.

Table 5. Hierarchical regression analysis assessing additional contribution of Health Literacy beyond Direct Attitude in predicting Intention to Obtain a Prostate Cancer Examination $(n=65)$

\begin{tabular}{|c|c|c|c|c|c|c|}
\hline \multirow{2}{*}{ Variable(s) in the Equation } & \multicolumn{2}{|c|}{ Unstandardized Coefficients } & \multicolumn{3}{|c|}{ Standardized Coefficients } & \multirow{2}{*}{$\begin{array}{l}\text { Collinearity Statistics } \\
\text { VIF }\end{array}$} \\
\hline & B & Std. Error & Beta & $t$ & $p$ & \\
\hline Direct Attitude & 1.10 & .177 & .606 & 6.24 & $<.001$ & 1.000 \\
\hline Health Literacy Scores & 255 & .095 & .249 & .267 & .008 & 1.003 \\
\hline
\end{tabular}

Table 6. Hierarchical regression analysis assessing additional contribution of Health Literacy in predicting Intention to Obtain a Prostate Cancer Examination beyond Normative Beliefs and Indirect Outcome Evaluation Direct Attitude $(\mathrm{n}=65)$

\begin{tabular}{|c|c|c|c|c|c|c|}
\hline \multirow{2}{*}{ Variable(s) in the Equation } & \multicolumn{2}{|c|}{ Unstandardized Coefficients } & \multicolumn{3}{|c|}{ Standardized Coefficients } & \multirow{2}{*}{$\begin{array}{l}\text { Collinearity Statistics } \\
\text { VIF }\end{array}$} \\
\hline & B & Std. Error & Beta & $t$ & $p$ & \\
\hline Indirect Outcome Evaluation & .653 & .239 & .264 & 2.74 & .008 & 1.007 \\
\hline Indirect Normative Beliefs & .697 & .119 & .564 & 5.86 & $<.001$ & 1.007 \\
\hline Health Literacy Scores & 236 & .096 & .228 & 2.47 & .016 & 1.003 \\
\hline
\end{tabular}

\section{Discussion}

Utilizing the Theory of Planned Behavior, this study sought to explore the predictors of the intent to screen (or not) for prostate cancer in incarcerated African American males. Specifically, it aimed to describe the knowledge, attitudes, behaviors, and behavioral intentions of the participants re-

Published by Sciedu Press garding prostate cancer screening. This research illuminated the factors that influence the decision-making process of African American males who are incarcerated in the federal prison system. The study also provides a better understanding of how the participant's perception of the behavior, his perceived control of performing the given behavior, and the 
importance of those who were important to him, affect that decision.

The findings suggest that the priorities of African American men who are incarcerated in the federal prison system may be slightly different from extant findings about non-incarcerated individuals. Variables such as marital status, age, and education were found to have no relationship with intention, which clearly contrasts with the literature on individual's intention to screen for prostate cancer. ${ }^{[26-28]}$ Incarceration may be playing a significant role here. Notably, individuals' self-assessment of health was also noted as not having a connection with one's intention to screen for prostate cancer. However, it is worth noting that the individuals who had family members diagnosed with prostate cancer in the past had a higher intention score than did those individuals who did not. This is consistent with current literature where men tend to over-estimate their chances of developing prostate cancer when a family member has been diagnosed with the disease. ${ }^{[29-31]}$

A significant amount of variance in the intention to obtain a prostate examination was explained by adding the health literacy scores to the model. This finding substantiates the important role of health literacy in people's ability to understand information and make informed decisions about screening. The literature supports this result, finding that limited health literacy can be a marker for vulnerability and a risk factor for poor health outcomes. ${ }^{[32,33]}$

Overall, this research provides an avenue for understanding the African American male inmate and giving researchers a glimpse into what influences this population to engage in the informed decision-making process regarding prostate cancer screening. This research also bridges an important gap in informed decision-making for the prostate cancer screening literature by highlighting issues relevant to the inmate population. The findings in this study address a significant gap in the literature by obtaining preliminary data about informed decision-making in the inmate population and may form the foundation for future studies of this population. The study also reveals the important role of health literacy in this process. By improving the inmate population's health literacy, they will be more empowered to participate in their own health care and decision-making.

\section{Limitations}

There are some implicit limitations when researching a prison population. Given the inmates' incarceration, their answers may be impacted by the fear of repercussions from the prison administration. Thus, the study's findings cannot be generalized beyond the sample population who completed the entire study. Another limitation arises from the study's small sample size. Granted, the prison population presents unique sampling challenges relative to other populations. Still, future researchers should seek ways to increase the sample size to see whether the findings hold across various subpopulations.

\section{Conclusion}

The African American inmate population represents several immediate and future challenges for the U.S. prison system. It is increasingly common for inmates to be convicted in their later years and receive longer sentences. As a result, prisons are increasingly responsible for providing for their health care, which will only become more expensive with time. Counteracting this issue begins with understanding how healthcare providers can better predict health-related behaviors and foster proactive health attitudes in this population. With this information, healthcare providers may be able to empower inmates to make more informed decisions, which may lead to lower overall healthcare costs and more lives saved.

Improving informed decision-making begins with cultivating African American men's health literacy. Nurses and healthcare providers should also take the time, when possible, to understand the patient's knowledge level using open-ended questions. By demonstrating empathy and attentiveness, nurses and healthcare providers can potentially decrease a patient's decisional conflict and empower him to make an informed decision. Future research should focus on the degree to which increased knowledge produces improvements in health literacy in African American men's decision-making process regarding prostate cancer screening. Researchers should also focus on the impact of health literacy, relative to other factors, on African American men's decision-making. Likewise, it would also be valuable to better understand the factors that inspire African American inmates to engage in the decision-making process, as well as those factors that motivate them to achieve greater health literacy (e.g., subjective norms, attitude toward a behavior, perceived control, education, age, etc.).

\section{CONFlicts of InTEREST Disclosure}

The author declares that there is no conflict of interest. 


\section{REFERENCES}

[1] American Cancer Society. Key Statistics for Prostate Cancer [Internet]. The American Cancer Society; n.d. [updated 2020 Jan 8; cited 2019 Jun 15]. Available from: https ://www. cancer.org/cance r/prostate-cancer/about/key-statistics.html

[2] Author. Surveillance, Epidemiology, and End Results (SEER) Program. Washington, DC: National Cancer Institute; n.d. [cited 2019 Jun 15]. Available from: http://seer.cancer.gov

[3] DeSantis CE, Siegel RL, Sauer AG. Cancer statistics for African Americans, 2016: Progress and opportunities in reducing racial disparities. CA: A Cancer Journal for Clinicians. 2016 Feb 22; 66(4): 290-308. PMid:26910411 https://doi.org/10.3322/caac. 2 1340

[4] Siegel RL, Miller KD, Jemal A. Cancer statistics, 2017. CA: A Cancer Journal for Clinicians. 2017 Jan 5; 67(1): 7-30. PMid:28055103 https://doi.org/10.3322/caac. 21387

[5] Tsodikov A, Gulati R, de Carvalho TM, et al. Is prostate cancer different in black men? Answers from three natural history models. Cancer. 2017 Jun 15; 123(12): 2312-2319. PMid:28436011 https://doi.org/10.1002/cncr. 30687

[6] Bronson J, Carson A. Prisoners in 2017 [Internet]. Washington, DC: Bureau of Justice Statistics; 2019 Apr 25 [cited 2019 Jun 15]. Available from: https://www.bjs.gov/index.cfm?ty=pbdet ail\&iid $=6546$

[7] Gramlich J. The gap between the number of blacks and whites in prison is shrinking [Internet]. Washington, DC: Pew Research Center; 2019 Apr 30. Available from: https : //www . pewresearc h.org/fact-tank/2019/04/30/shrinking-gap-between-n umber-of-blacks-and-whites-in-prison/

[8] Holt CL, Le D, Saunders DR, et al. Informed decision-making and satisfaction with a church-based men's health workshop series for African-American men: Men-only vs. mixed-gender format. Journal of Cancer Education. 2015 Sept; 30(3): 530-534. PMid:25330866 https ://doi.org/10.1007/s13187-014-0731-x

[9] Sandiford L, D'Errico EM. Facilitating shared decision making about prostate cancer screening among African American men. Oncology Nursing Forum. 2016 Jan; 43(1): 86-92. PMid:26679448 https://doi.org/10.1188/16.0NF.86-92

[10] Owens OL, Felder T, Tavakoli AS, et al. Evaluation of a computerbased decision aid for promoting informed prostate cancer screening decisions among African American men: iDecide. American Journal of Health Promotion. 2018 Jul 11; 33(2): 267-278. PMid:29996666 https://doi.org/10.1177/0890117118786866

[11] Owens OL, Jackson DD, Thomas TL, et al. Prostate Cancer Knowledge and Decision Making Among African-American Men and Women in the Southeastern United States. International Journal of Men's Health. 2015 Jul 17; 14(1): 55-70.

[12] Ingram RR. Creating "Win-Win" Outcomes for Patients with Low Health Literacy: A Nursing Case Study. MEDSURG Nursing 2018 Mar; 27(2): 132-134.

[13] Author. National Action Plan to Improve Health Literacy [Internet]. Washington, DC: U.S. Department of Health and Human Services, Office of Disease Prevention and Health Promotion; 2010 [cited 2019 Feb 20]. Available from: https://health.gov/our-work/health-literacy/nation al-action-plan-improve-health-literacy

[14] Woody DS. Health Literacy: Answering the "Call". Virginia Nurses Today. 2019 May; 27(2): 1-9.

[15] Loeb SJ, AbuDagga. A Health-related research on older inmates: An integrative review. Research in Nursing \& Health 2006 Dec; 29(6): 556-565. PMid:17131280 https ://doi.org/10.1002/nu r. 20177

Published by Sciedu Press
[16] Aday RH. Aging prisoners: Crisis in American corrections. Westport, CT: Praeger Publishers; 2003, 240 p.

[17] Chammah M. Do you age faster in prison? Science tries to catch up with the problem of "Accelerated aging" [Internet]. New York (NY): The Marshall Project; 2015 Aug 24 [cited 2019 Feb 15]. Available from: http: //www. themarshallproject.org

[18] Author. The Impact of an Aging Inmate Population on the Federal Bureau Of Prisons [Internet]. Washington, DC: U.S. Department of Justice, Office of the Inspector General; 2015 [cited 2019 Feb 20]. Available from: https://nicic.gov/impact-aging-inm ate-population-federal-bureau-prisons-2016

[19] Ajzen I. The Theory of Planned Behavior. Organizational Behavior and Human Decision Processes. 1991 Dec; 50(2): 179-211. https ://doi.org/10.1016/0749-5978(91)90020-T

[20] Gregory DJ. Iowa men's decision-making process for prostate cancer prevention via screening with the prostate -specific antigen (PSA) test [dissertation]. Iowa City, IA: University of Iowa; 2007. 296 p.

[21] Francis JJ, Eccles MP, Johnston M, et al. Constructing Questionnaires Based on the Theory of Planned Behaviour: A Manual for Health Services Researchers [Internet]. Newcastle, UK: Centre for Health Services Research [cited 2019 Jun 10]. Available from: https ://openaccess.city.ac.uk/id/eprint/1735/

[22] Pfizer. The Newest Vital Sign [Internet]. New York: Pfizer, Inc. c2002-2020 [cited 2018 Feb 10]. Available from: https://www.pfizer.com/health/literacy/public-p olicy-researchers/nvs-toolkit

[23] Baker DW, Wolf MS, Feinglass J, et al. Health literacy and mortality among elderly persons. Archives of Internal Medicine 2007 Jul 23; 167(14): 1503-1509. PMid:17646604 https://doi.org/10.100 1/archinte.167.14.1503

[24] Weiss BD, Mays MZ, Martz W, et al. Quick Assessment of Literacy in Primary Care: The Newest Vital Sign. Annals of Family Medicine. 2005 Nov; 3(6): 514-522. PMid:16338915 https : //doi.org/10.1370/afm. 405

[25] Polit DF, Beck CT. Nursing research: generating and assessing evidence for nursing practice. Tenth edition. Philadelphia: Wolters Kluwer Health; 2007; 784 p.

[26] Jackson DD, Owens OL, Friedman DB, et al. An intergenerational approach to prostate cancer education: Findings from a pilot project in the southeastern USA. Journal of Cancer Education. 2014 Dec; 29(4): 649-656. PMid:24557505 https ://doi .org/10.1007/s1 3187-014-0618-x

[27] Plowden KO. To screen or not to screen: Factors influencing the decision to participate in prostate cancer screening among urban African-American men. Urologic Nursing. 2006 Dec; 26(6): $477-$ 482.

[28] Williams RM, Zincke NL, Turner RO, et al. Prostate cancer screening and shared decision-making preferences among African-American members of the Prince Hall Masons. Journal of Psychosocial Oncology. 2008 Oct; 17(10): 1006-1013. PMid:18203246 https : //doi.org/10.1002/pon.1318

[29] Bancroft EK, Castro E, Bancroft GA, et al. The psychological impact of undergoing genetic-risk profiling in men with a family history of prostate cancer. Psycho-Oncology. 2015 Apr 14; 24(11): 1492-1499. PMid:25872100 https://doi .org/10.1002/pon.3814

[30] Altin SV, Stock S. The impact of health literacy, patient-centered communication and shared decision-making on patients' satisfaction with care received in German primary care practices. BMC Health Services Research. 2016 Aug 30; 16: 450-460. PMid:27577702 https://doi.org/10.1186/s12913-016-1693-y

[31] Beebe-Dimmer JL, Wood DP Jr, Gruber SB, et al. Risk perception and concern among brothers of men with prostate carcinoma. 
Cancer. 2004 Apr 1; 100(7): 1537-1544. PMid:15042690 https : //doi.org/10.1002/cncr. 20121

[32] Jacobsen PB, Lamonde LA, Honour M, et al. Relation of family history of prostate cancer to perceived vulnerability and screening behavior. Psycho-Oncology. 2004 Feb; 13(2): 80-85. PMid:14872526 https://doi.org/10.1002/pon.760

[33] Brabers A, Rademakers J, Groenewegen P, et al. What role does health literacy play in patients' involvement in medical decisionmaking? PLOS ONE. 2017 Mar 3; 12(3): e0173316. PMid:28257472 https://doi.org/10.1371/journal. pone.0173316 